\title{
Design and Optimization of Front Suspension of FSAE based on ADAMS Simulation
}

\section{Du Canyi ${ }^{1, \text { a }}$, Zhu Baochai ${ }^{1, b}$, Wang Hengbo ${ }^{1, c}$, Mai Xingye ${ }^{1, d}$ and Qin Taixing ${ }^{1,}$}

School of Automotive Engineering, Guangdong Polytechnic Normal University, Guangzhou, China aemail: micandu@163.com, bemail: 1304112919@qq.com, 'email: 172223862@qq.com, ${ }^{\mathrm{d}} \mathrm{email}:$ 1029173990@qq.com, eemail: 924763257@qq.com

Keywords:FSAE, Front Suspension, Simulation Analysis, Multi-objective Optimization Analysis. Abstract. Making a virtual design and optimization of Front suspension aimed at FSAE. Based on parameter calculation and design of front suspension and use the ADAMS/Car to make a simulation analysis to get the unreasonable function parameters as the objectives basis of the optimization. Determine design variables, design objectives, objective function and constraints in ADAMS/Insight to make a emulation experiment and multi-objective optimization design of front suspension. According to the result of the simulation optimization, modified model parameters and did the kinematics simulation analysis to acquire the the kinematic characteristics before and after optimization. The result shows that the main function of front Suspension improved obviously after simulation.

\section{Introduction}

The front suspension plays an important role to automobile handling stability and ride comfort. Therefore the system design and optimization of Front Suspension are the important part of FSAE [1]. It is commonly uses the double cross arm active suspension model due to its performance parameters such as wheel alignment and fix-frequency of front suspension are essential for the automobile handling stability. The paper uses the ADAMS to make a simulation analysis and optimization of the front suspension function and provides theoretical basis and method for the front suspension design ${ }^{[2]}$.

\section{Kinematic Model of Front Suspension}

Based on FSAE 2012.cdb, according to the hard point coordinates from the front suspension design parameters and relevant design to establish the modification of kinematic modeling of front suspension $^{[3]}$, as shown in Fig.1.

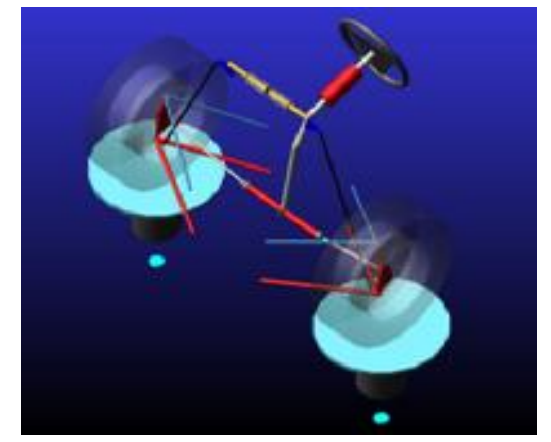

Fig.1 Kinematics simulation model of front suspension 


\section{Simulation result and analysis before optimization}

Before the kinematic analysis, first of all, set the parameters of the car, such as type rolling radius, sprung mass wheel base and so on. Set the simulation parameter to make a front suspension simulation experiment of beating parallel and calculate the parameters of wheeling alignment and wheel-track Front Suspension beating and the change of the wheel up and down to judge the front Suspension beating stroke ${ }^{[4]}$, set the step length of $30 \mathrm{~mm}$, up and down $40 \mathrm{~mm}$ randomly . After the simulation, use ADAMS own drawing characteristics an output parameters curve of the performance of multiple representations of the front suspension.

Camber Angle. The proper camber angle can ensure the handling stability of the tire. If the angle changes too much, it will reduce lateral adhesion of tire, so that it need to minimize the change of the camber angle ${ }^{[5]}$. When the car wheeling is beating with the body. In the common wheel jumping range, its change is generally controlled with $1.5 / 80 \mathrm{~mm}$. The change curve of the camber angle when the wheel jumping, as shown in Fig.2.

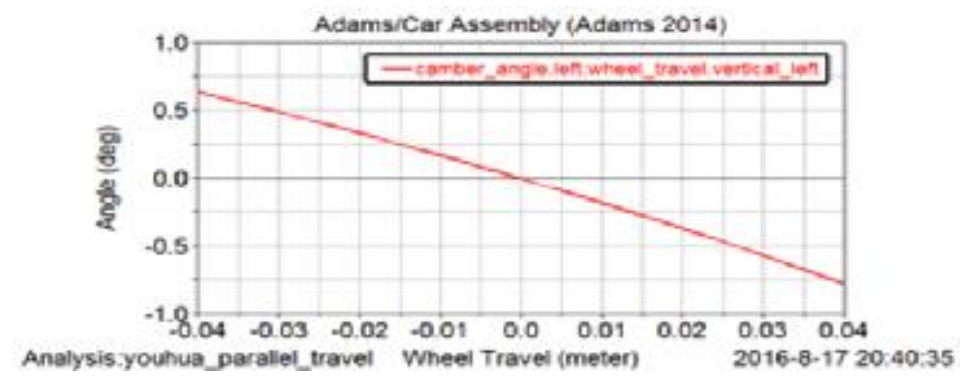

Fig.2 Change curve of the camber angle when the wheel jumping

The design value of camber angle of the wheel in the static balance position is -1, when the wheel jumping, it changes 1.25 totally in the range of the Front Suspension jumping stroke.

Kingpin inclination angle. The kingpin inclination has the automatic return function and can reduce steering distance but meanwhile when the wheeling turning, it will enlarge the camber angle. When the trend enlarge, it will reduce the wheel grip, therefore this change cannot be large. The change curve of kingpin inclination angle, as shown in Fig.3, when the wheel up and down in $40 \mathrm{~mm}$ the kingpin inclination angel in the static balance position changes from $4.165^{\circ}$ to $4.465^{\circ}$.

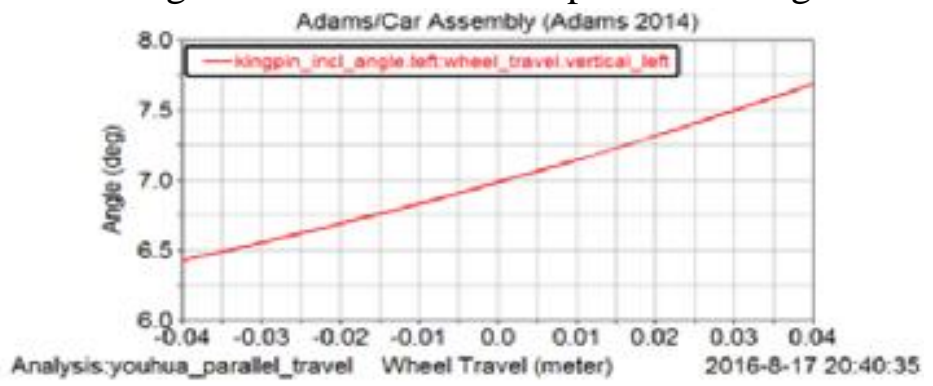

Fig.3 Change curve of kingpin inclination angle when the wheel jumping

Toe angle of the front wheel. The toe angle changing too much will influence the straight riding stability and aggravate the wear of the tire. Therefore the angle of the wheels as shown in Fig.4, the design value of the toe angle in the static balance position is $-1^{\circ}$, when the wheeling dumping in 40 $\mathrm{mm}$, the toe angle changes $1^{\circ}$ totally in the limit range of Front Suspension stroke. 


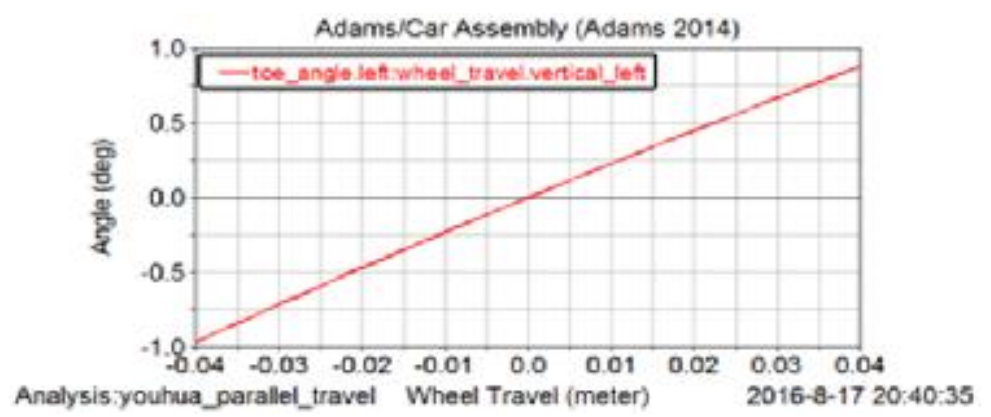

Fig.4 Change curve of front wheel toe angle when the the wheel jumping

Caster angle. In the independent suspension when the car goes on the rough road surface, the wheel up and down will cause the change of the wheel-track. It will cause the tire wears more or less (the change more, the wear more) in order to reduce the wear of the tire, it hopes to get the wheel-track change as small as possible. When the wheeling jumping, as shown in Fig.5, in the static balance position the front distance is $1240 \mathrm{~mm}$, more $10 \mathrm{~mm}$ than original design value. It is because the Front Suspension set $0^{\circ}$ camber angle to lead to the reason for both side of the wheel center to move outside. The Front Suspension up an down at $40 \mathrm{~mm}$, the wheel grounding distance ranges from $1228 \mathrm{~mm}$ to $1240 \mathrm{~mm}$. the variation is $12 \mathrm{~mm}$, it shown the large amount of side-slip of the front wheel distance and it need to optimization.

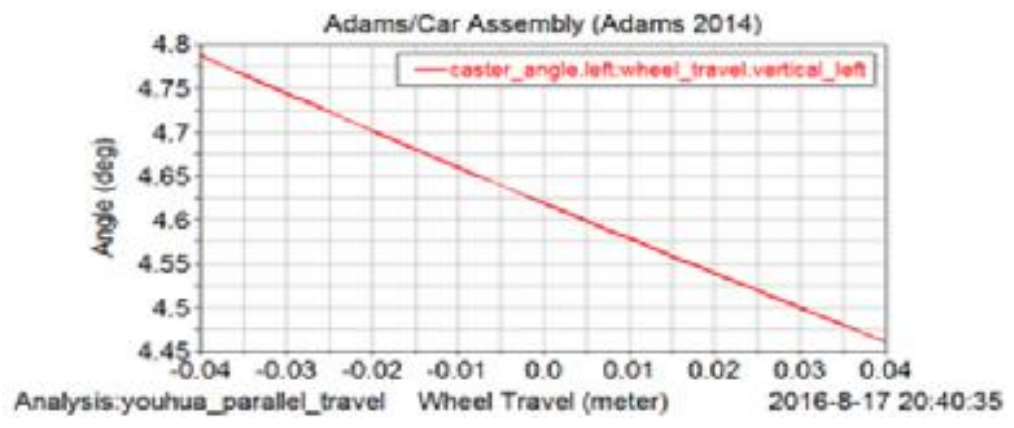

Fig.5 Change curve of caster angle when the the wheel jumping

\section{The Multi-objective optimization design of the Front Suspension}

From the result of the simulation, the camber angle, kingpin inclination angle, toe angle, caster angle change rang is not ideal with the wheel up and down and various parameters have a certain influence on the relationship with each other. Therefore, use ADAMS/Insight to optimize the Front Suspension through the experimental design and the multi-objective optimization methods and finally get the optimization suspension hard point parameters.

Set the optimization targets and analysis. In the ADAMS/Insight optimization analysis function interface, to fix the multiple design variables that are less affected by the objective and set each expected target value and the corresponding weight coefficient, the optimization method is weighted sum of squares. The part of the result of the optimization, as shown in Table 1 and Fig.6 (a)\&(b). 
Table 1 Initial and optimized values of coordinates design variables of the front suspension(mm)

\begin{tabular}{c|c|c}
\hline Design variable & $\begin{array}{c}\text { Coordinate initial } \\
\text { value }\end{array}$ & $\begin{array}{c}\text { Coordinate optimization } \\
\text { value }\end{array}$ \\
\hline $\begin{array}{c}\text { The z-coordinate of the front control point of } \\
\text { the upper control arm }\end{array}$ & 200 & 205 \\
\hline $\begin{array}{c}\text { The z-coordinate of the upper control arm } \\
\text { The z-coordinate of the lower control arm }\end{array}$ & 200 & 205 \\
\hline $\begin{array}{c}\text { The z-direction coordinates of the lower } \\
\text { control arm }\end{array}$ & 0 & -5 \\
\hline Coordinates of the z-direction in the tie rod & 35 & 30 \\
\hline
\end{tabular}
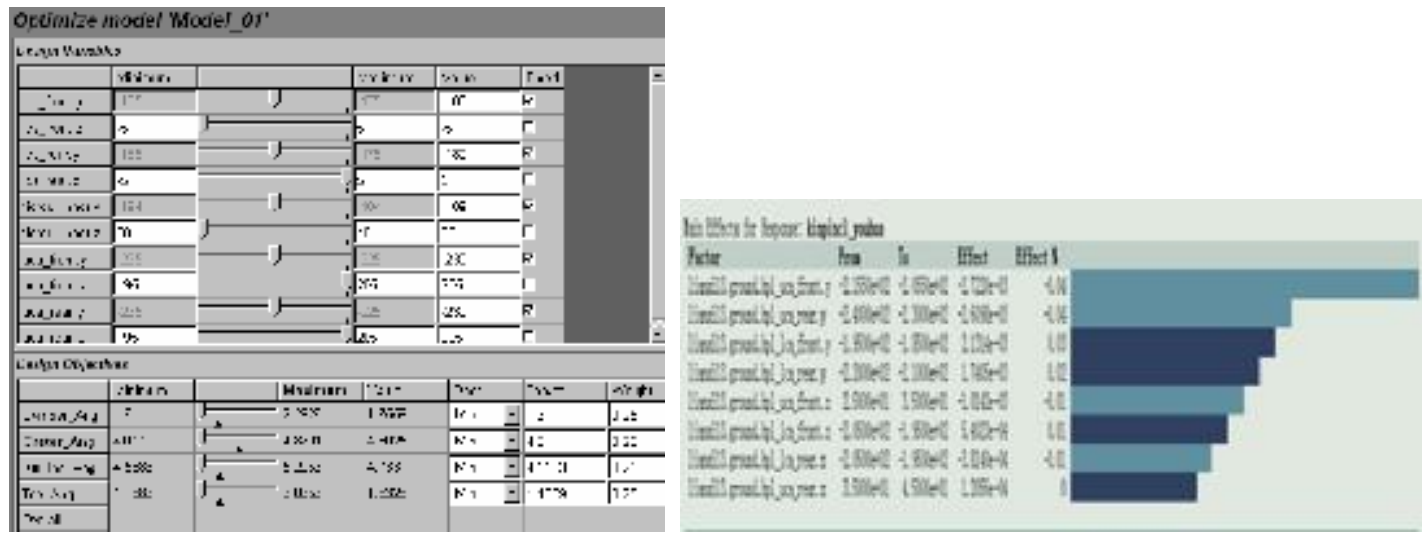

(a) Optimized result of front suspension (b) Influence of optimized variables on the kingpin inclination angle Fig.6 Parts of optimized results

\section{Comparison of kinematic characteristics before and after optimization}

According to the optimization result before, modify the corresponding hard point coordinate of the suspension, set the same optimization parameters, make a simulation experiment to get the various change curve after the optimization and make a comparison of the suspension kinematic performance of suspension optimization before.

Camber angle. The change curve of the camber angle with wheel up and down before and after optimization, as shown in Fig.7. The camber angle variation after optimization is $0.12^{\circ}$, was $1.18^{\circ}$ than the before optimization variation. The change trend is in accordance with the change design requirements when the wheel up and down, the result of optimization is better.

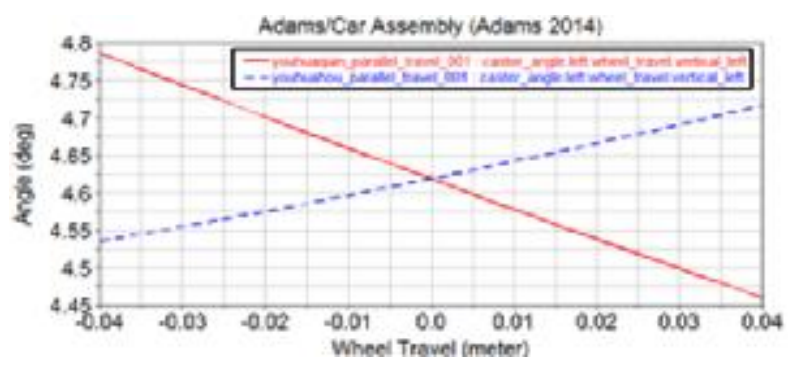

Fig.7 Comparison of the camber angle changes before and after optimization

Kingpin inclination angle. The change curve of the kingpin inclination angle before and after optimization, as shown in Fig.8, the variation after optimization is $1.2^{\circ}$, less $0.1^{\circ}$ than the variation before optimization, the result of the optimization is better. The change trend is in accordance with the design requirements when the wheel, but not accordance when the wheel down. 


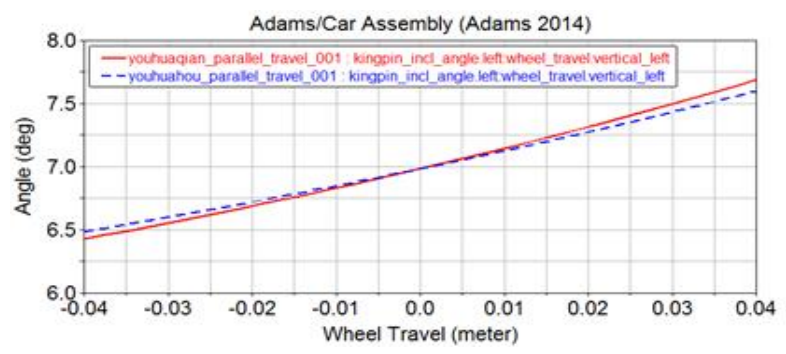

Fig.8 Comparison of the kingpin inclination changes before and after optimization

Toe angle of front wheel. The change curve of toe angle of front wheel before and after optimization, as shown in Fig.9, the toe angle is in the vicinity of values, and the change range is small, the same as before optimization comparison of the before and after the optimization. After the front suspension by multi-objectives analysi, the change range about the toe angle of front wheel has reduced and lead to the obviously improve of the brake antibody performance, meanwhile it verify the validity and correctness of the multi-objective design method.

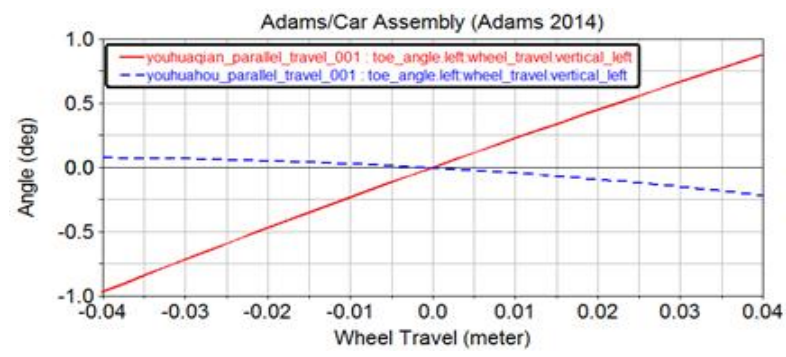

Fig.9 Comparison of the front toe angle changes before and after optimization

Kingpin angle. Before and after optimization of the kingpin with the wheels up and down after the jump when the curve shown in Fig.10. The optimized range of inclination angle is very small in the range of 0 to $40 \mathrm{~mm}$, and the optimization effect is obvious.

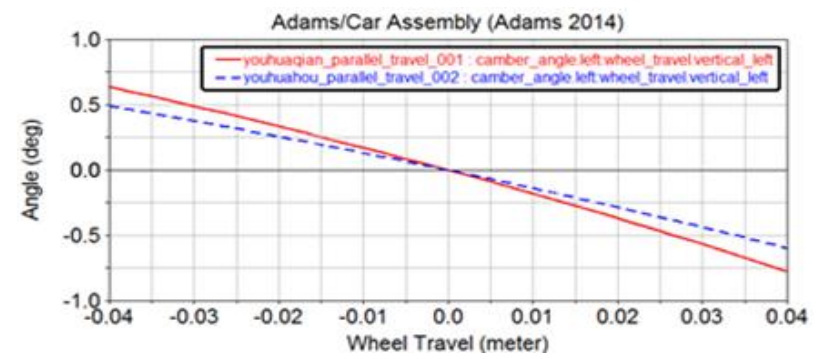

Fig.10 Comparison of the kingpin caster angle changes before and after optimization

In summary, the performance parameters of the front and rear suspension parameters, such as wheel camber angle, kingpin inclination angle, front toe toe angle and kingpin pitch angle, are all reduced with the variation of wheel runout. Nodal performance has been significantly improved, but also verify the multi-objective optimization design method is valid and correct.

\section{Conclusions}

Use ADAM/car to make modeling and simulation of analog prototype of FSAE racing double cross arm independent suspension and final the existential question of the suspension is the variation of the camber angle and kingpin inclination angle is too large. Use ADAMS/ Insight to make a optimization design, ensure the camber angle, kingpin inclination angle, toe angle and caster angle as the design target and ensure the relevant design variation to get the influence degree of each design variable to each design goal. Use the software to get the optimization result shows the four 
wheel alignment parameters, the distance between the vehicle and the wheel is obviously reduces and it is beneficial to the handling stability of the vehicle, and provide a method and the technical support for further research and suspension.

\section{Acknowledgements}

This work was financially supported by the Excellent Young Teachers Program in Higher Education of Guangdong, China (Yq2014110) and Foundation for Distinguished Young Talents in Higher Education of Guangdong, China (2014KQNCX176).

\section{References}

[1] Huang Jiewen, Huang Juhua. Dynamic Simulation and Analysis of Double Wishbone Suspension Using ADAMS/car [J]. Modern Manufacturing Engineering, 2010,31 (3): 127-129.

[2] Liu Hong, Wang Qidong. Based on ADAMS to dynamic simulation and analysis of double cantiever[J]. Journal of the Heifei university of technology, 2007, 30 (1): 57-59.

[3] Yu Haifeng, Yu Xuebing. Ased on ADA MS to dynamic simulation and analysis of double cantiever[J]. Amechanical design and guidance, 2007 (10): 56-58.

[4]Chan Jun. Examples of technology and engineering analysis[M]. China Water Conservancy and Electric power press, 2008.

[5]Ju Tian xing fu, Du bian heng san , Guang gen tai lang . the guide of automotive engineering[M] , translator : Wang Lirong. Beijing:China Manchine Press, 2011.1. 